\title{
Insulin-Dependent Leptin Expression in Breast Cancer Cells
}

\author{
Viviana Bartella, ${ }^{1,2}$ Sandra Cascio, ${ }^{1,3}$ Elena Fiorio, ${ }^{1,4}$ Alessandra Auriemma, ${ }^{1,4}$ \\ Antonio Russo, ${ }^{3}$ and Eva Surmacz ${ }^{1}$ \\ 'Sbarro Institute for Cancer Research and Molecular Medicine, Temple University, Philadelphia, Pennsylvania; ${ }^{2}$ Department \\ of Pharmaco-Biology, University of Calabria, Cosenza, Italy; ${ }^{3}$ Department of Surgical and Oncological Sciences, \\ Section of Medical Oncology, University of Palermo, Palermo, Italy; and ${ }^{4}$ Department of Medical \\ Oncology, University of Verona, Verona, Italy
}

\begin{abstract}
Pathologic conditions associated with hyperinsulinemia, such as obesity, metabolic syndrome, and diabetes, seem to increase the risk of breast cancer. Here, we studied molecular mechanisms by which insulin activates the expression of leptin, an obesity hormone that has been shown to promote breast cancer progression in an autocrine or paracrine way. Using MDA-MB-231 breast cancer cells, we found that $(a)$ insulin stimulated leptin mRNA and protein expression, which was associated with increased activation of the leptin gene promoter; (b) insulin increased nuclear accumulation of transcription factors hypoxia inducible factor (HIF)-1 $\alpha$ and Spl and their loading on the leptin promoter; (c) small interfering RNA (siRNA)-mediated knockdown of either HIF-1 $\alpha$ or Spl significantly down-regulated insulin-induced leptin mRNA and protein expression; further inhibition of leptin expression was observed under the combined HIF-1 $\alpha$ and Spl siRNA treatment; $(d)$ inhibition of extracellular signal-regulated kinase (ERK)1/2 and phosphatidylinositol3-OH kinase (PI-3K) pathways significantly, albeit partially, decreased insulin-dependent leptin mRNA and protein expression, which coincided with reduced association of HIF-1 $\alpha$ and/or Spl with specific leptin promoter regions; and (e) inhibition of ERK1/2 reduced recruitment of both HIF-1 $\alpha$ and Spl to the leptin promoter, whereas down-regulation of PI-3K influenced only HIF-1 $\alpha$ binding. In summary, our data suggest that hyperinsulinemia could induce breast cancer progression through leptin-dependent mechanisms. In MDA-MB-231 cells, this process requires Sp1- and HIF$1 \alpha$-mediated leptin gene transcription and is partially regulated by the PI-3K and ERK1/2 pathways. [Cancer Res 2008;68(12):4919-27]
\end{abstract}

\section{Introduction}

Recent epidemiologic reports suggested that general obesity is associated with an increased risk of developing breast cancer in postmenopausal women, whereas central obesity can increase breast cancer risk in both premenopausal and postmenopausal populations $(1,2)$. The molecular mechanisms underlying the obesity-breast cancer link are not clear, but it is thought that one important factor might be excess exposure of mammary epithelium to various bioactive substances (for instance, estrogens and

Note: V. Bartella and S. Cascio contributed equally to this work.

Requests for reprints: Eva Surmacz, Sbarro Institute for Cancer Research and Molecular Medicine, 1900 North 12th Street, BioLife Building, Room 446, Philadelphia, PA 19122. Phone: 215-204-0306; Fax: 215-204-0303; E-mail: surmacz@temple.edu.

C 2008 American Association for Cancer Research.

doi:10.1158/0008-5472.CAN-08-0642 growth factors) synthesized by the adipose tissue (2-5). The principal hormone produced by adipocytes is leptin (6). Leptin, the product of the $(o b)$ gene, is best known as a regulator of food intake and energy expenditure via hypothalamic-mediated effects (6). However, leptin also controls other processes such as reproduction, lactation, hematopoiesis, immune responses, cell differentiation, proliferation, survival, and angiogenesis (6). Furthermore, there is evidence that leptin can be involved in neoplastic processes (7). Data obtained using breast cancer cellular and animal models suggested that leptin can stimulate cell growth, survival, and transformation, and interfere with the action of antiestrogens $(2,3$, $5,7-9)$.

Recently, we and others reported that leptin and its receptor (ObR) are overexpressed in breast cancer relative to noncancer mammary epithelium (10-12), which indicates that leptin can influence breast cancer cells not only by endocrine and/or paracrine actions but also through autocrine pathways. We also showed that overexpression of leptin and ObR mRNA in breast cancer could be induced by high doses of insulin (10). Interestingly, although insulin was a major stimulant of leptin in less differentiated estrogen receptor- $\alpha$ (ER)-negative MDA-MB-231 cells, it only modestly up-regulated leptin mRNA in less aggressive ER-positive MCF-7 cells (10). Because hyperinsulinemia, one of the characteristics of obesity, diabetes, and metabolic syndrome, has been associated with increased breast cancer risk $(4,13,14)$, we set out to investigate the mechanism by which insulin up-regulates leptin expression in ER-negative breast cancer cells.

The human leptin gene promoter (from -2931 to +1 ) contains multiple transcription regulatory elements that can be activated by insulin. These include seven Spl binding sites (GC boxes) and eight binding sties for hypoxia inducible factor (HIF; ref. 15). Spl is a ubiquitous nuclear factor that mediates the effects of insulin in different cell types, regulating such processes as glucose metabolism, lipid biosynthesis (16-18). The abundance of nuclear Spl has been shown to be increased by insulin and can be posttranslationally regulated by phosphatidylinositol-3-OH kinase (PI-3K) and extracellular signal-regulated kinase (ERK) $1 / 2$ pathways in some cell models (19-21).

HIF is a transcription factor of major importance in cellular response to oxygen deficiency, as it acts as a master regulator of genes involved in tissue reoxygenation (22). In addition, HIF is known to facilitate cancer progression by promoting tumor neoangiogenesis, cell motility, and invasion (23). HIF is a heterodimer consisting of a constitutively expressed HIF-1 $\beta$ subunit and an oxygen-regulated, unstable HIF-l $\alpha$ subunit. HIF interactions with DNA are mediated through Hypoxia-Responsive Elements (HRE; 5'-RCGTG-3'; ref. 22). HIF activation involves HIF-1 $\alpha$ stabilization, which occurs either due to hypoxia or under normoxia upon activation of different signaling pathways, for instance, the insulin-responsive PI-3K/mammalian target of 
rapamycin and ERK1/2 cascades $(24,25)$. Importantly, ERK1/2 may also phosphorylate and activate the histone acetyltransferase p300 (26-28), a common coactivator of Spl and HIF (28-30), leading to increased transcriptional activity of both factors. HIF and Spl have been implicated in the regulation of the leptin promoter in noncancer tissues $(17,31)$, according to our recent work, HIF can induce leptin gene in breast cancer cells (32).

Here, we show that in MDA-MB-231 breast cancer cells, insulininduced up-regulation of leptin expression is regulated by PI-3K and ERK1/2 and depends on Spl and HIF-1 $\alpha$ interactions with specific regions in the leptin promoter.

\section{Materials and Methods}

Cell culture and treatments. MDA-MB-231 cells were grown in DMEM: F12 (Cellgro) containing 5\% calf serum. The cultures were synchronized in phenol red-free serum-free medium for $24 \mathrm{~h}$ and then stimulated with $340 \mathrm{nmol} / \mathrm{L}$ insulin (Sigma) for 4 or $16 \mathrm{~h}$, depending on the experiment. LY294002 (LY; Calbiochem) at $50 \mu \mathrm{mol} / \mathrm{L}$ was used to inhibit PI-3K, whereas UO00126 (UO; Calbiochem) at $5 \mu \mathrm{mol} / \mathrm{L}$ was used to down-regulate ERK1/2 activity. These doses were identified before as the most effective, nontoxic concentrations for MDA-MB-231 cells (33).

Western blotting. The cells were stimulated with $340 \mathrm{nmol} / \mathrm{L}$ insulin for $4 \mathrm{~h}$ and then lysed to obtain cytoplasmic and nuclear proteins, as described before (34). The expression of proteins was analyzed in $70 \mu \mathrm{g}$ of cytoplasmic or nuclear cell lysates. The following antibodies (Ab) were used for Western blotting (WB): HIF-1 $\alpha$ monoclonal (m)Ab (B\&D systems); Sp1 (PEP2) polyclonal (p)Ab (Santa Cruz Biotechnology); anti- $\beta$-tubulin H235 (Santa Cruz); and nucleolin mAb (Santa Cruz). The proteins were separated on a $4 \%$ to $15 \%$ polyacrylamide gel, immunoblotted, and quantified as described before (34).

Luciferase reporter assays. Luciferase assays were performed as described before (34). In brief, MDA-MB-231 cells grown in 6-well plates were transfected for $6 \mathrm{~h}$ with $0.5 \mu \mathrm{g}$ DNA mixture per well using Fugene 6 (Roche). The transfection mixtures contained $0.3 \mu \mathrm{g}$ of either the leptin promoter reporter plasmid pGL3-Obl encoding the firefly luciferase (Luc) cDNA under leptin promoter (from -2924 to +31 ; ref. 35 ) or the empty vector pGL3. To control transfection efficiency, the cells were cotransfected with $50 \mathrm{ng}$ of pRL-TK-Luc, a plasmid encoding Renilla luciferase (RI Luc; Promega). Upon transfection, the cells were treated with $340 \mathrm{nmol} / \mathrm{L}$ insulin for $4 \mathrm{~h}$, or left untreated. Luciferase activity (Luc and RI Luc) in cell lysates was measured using Dual Luciferase Assay System (Promega) following the manufacturer's instructions and quantified as described previously (34). All experiments were repeated at least four times.

Chromatin immunoprecipitation. We followed chromatin immunoprecipitation (ChIP) methodology described in detail previously (34). MDAMB-231 cells were treated with $340 \mathrm{nmol} / \mathrm{L}$ insulin and/or $50 \mu \mathrm{mol} / \mathrm{L} \mathrm{LY}$, $5 \mu \mathrm{mol} / \mathrm{L}$ UO for $4 \mathrm{~h}$, or left untreated. Next, the cells were crosslinked with $1 \%$ formaldehyde, and chromatin was collected and sonicated. Soluble chromatin was immunoprecipitated with the following Abs: HIF- $1 \alpha$ pAb (Santa Cruz), Spl pAb (Santa Cruz), p300 pAb (Upstate Biotechnology), and Histone 3 (H3) pAb (Upstate Biotechnology). DNA-protein immune complexes were eluted, reverse crosslinked, and DNA was extracted. The presence of leptin promoter domains containing HRE and Spl motifs in immunoprecipitated DNA was identified by PCR using the following primers: Lepl (region from -992 to +377): forward, 5'-GCGCAGTGGGGACCAGAA-3' and reverse, 5'-CACCACCTCTGTGGAGTAG-3'; Lep2 (region from -2742 to -1403 ): forward, 5'-AAAGGGCCAGGTAGAAAACAT-3'; reverse, 5'-GTTTGGTAATGCCCAAAAGCT-3'. The primers for the glyceraldehyde-3-phosphate dehydrogenase promoter were as follows: forward, 5'-GCTACTAGCGGTTTTACGGG-3' and reverse, 5'-AAGATGCGGCTGACTGTCGAA-3'. The PCR conditions for Lepl region were as follows: $1 \mathrm{~min}$ at $94^{\circ} \mathrm{C}, 1 \mathrm{~min}$ at $53^{\circ} \mathrm{C}$, and $1 \mathrm{~min} 20 \mathrm{~s}$ at $72^{\circ} \mathrm{C}$. For Lep2 region, the PCR conditions were as follows: $1 \mathrm{~min} 94^{\circ} \mathrm{C}, 1 \mathrm{~min}$ at $60^{\circ} \mathrm{C}$, and $1 \mathrm{~min}$ at $72^{\circ} \mathrm{C}$. The amplification of Lep regions was analyzed after PCR 32 cycles. In control samples, the primary Abs were replaced with nonimmune rabbit IgG. All experiments were repeated at least thrice.

DNA affinity precipitation assay. Binding of nuclear HIF- $1 \alpha$ and $\mathrm{Spl}$ to their specific responsive elements on Lepl (region -602 to -631 for HIF-l $\alpha$ and region -354 to -323 for Sp1) and on Lep2 (region -2592 to -2562 for HIF- $1 \alpha$ and region -2540 to -2510 for Spl) was assessed using DNA affinity precipitation assay (DAPA) protocol described before $(32,36)$. Briefly, $100 \mu \mathrm{g}$ of nuclear proteins obtained from cells stimulated with $340 \mathrm{nmol} / \mathrm{L}$ insulin and/or $50 \mu \mathrm{mol} / \mathrm{L} \mathrm{LY,} 5 \mu \mathrm{mol} / \mathrm{L}$ UO for $4 \mathrm{~h}$ were mixed with $2 \mu \mathrm{g}$ of specific biotinylated DNA HRE probes in $400 \mu \mathrm{L}$ of Buffer D $(32,36)$ and then precipitated with $50 \mu \mathrm{L}$ of streptavidin-agarose beads (Invitrogen). Upon removal of beads, supernatants were analyzed for the presence and abundance of HIF- $1 \alpha$ and Spl by WB. The specific HRE probes were prepared by annealing a biotinylated sense oligonucleotide (HRE-1, HRE-2, and HRE-3) with the corresponding nonbiotinylated antisense oligonucleotide. The pairs for Lepl were as follows: for HIF- $1 \alpha, 5^{\prime}$-Bio-TCCAGAGAGCGTGCACTCCCTGGGTGCCA-3' and 5'-TGGCACCCAGGGAGTGCACGCTCTCTGGA-3'; for Sp1, 5'-Bio-CTCACAGCCACCCCCGCCCGGACCGCGCCCC-3' and 5'-GGGGCGCGGTCCGGGCGGGGGTGGCTGTGAG-3'. The pairs for Lep2 were as follows: for HIF- $1 \alpha$, 5'-Bio-GTAATTTTCCCGTGAGAACTATTCTTCTTT-3' and 5'-AAAGAAGAATAGTTCTCACGGGAAAATTAC-3'; for Spl, 5'-BioGCGCTGATCCTCCCGCCTCAGTCTCCCTAA-3' and 5' ${ }^{\prime}$-TTAGGGAGACTGAGGCGGGAGGATCAGCGC-3'. Unlabeled probes were used as negative controls. As an additional control, a 10-fold excess of unlabeled probes was added to the nuclear lysates $30 \mathrm{~min}$ before the addition of the labeled probes to block specific probe-protein interactions, as described before (36). All experiments were repeated at least thrice.

Leptin mRNA measurements by quantitative real-time PCR. MDAMB-231 cells were treated for $4 \mathrm{~h}$ with $340 \mathrm{nmol} / \mathrm{L}$ insulin, and/or $50 \mu \mathrm{mol} / \mathrm{L}$ $\mathrm{LY}, 5 \mu \mathrm{mol} / \mathrm{L}$ UO for $4 \mathrm{~h}$, or left untreated. For knockdown experiments, the cells were transfected with HIF- $1 \alpha$ siRNA and/or Spl siRNA (Applied Biosystems), as described below. Total cellular RNA was isolated using TRIzol reagent (Invitrogen). Three micrograms of total RNA were reverse transcribed using the Taq Man RT kit (Applied Biosystems) according to vendor's instructions. Two microliters of the RT products were used to amplify leptin sequences using the Hs00174877_ml Lep Taq Man kit (Applied Biosystems). To normalize quantitative real-time PCR (QRT-PCR) reactions, parallel Taq Man assays were run on each sample for $\alpha$-actin. Changes in the leptin mRNA content relative to $\alpha$-actin mRNA were determined using a threshold cycle (CT) method (ABI User Bulletin no. 2) to calculate changes in CT and, ultimately, fold and percent change. An average CT value for each RNA was obtained for replicate reactions.

Knockdown of HIF-1 $\alpha$ and Spl using small interfering RNA. HIF- $1 \alpha$ and Spl knockdowns were achieved with specific small interfering RNA (siRNA)s purchased from Ambion. HIF siRNA and/or Spl siRNA (150 nmol/L) was mixed with the transfection agent RNAiFect (Qiagen; siRNA to RNAiFect ratio, 1:3) and incubated for $15 \mathrm{~min}$ at room temperature. Then, the mixture was transfected into MDA-MB-231 cells for $6 \mathrm{~h}$. After that, the cells were placed in fresh medium for $24 \mathrm{~h}$. Next, the cells were treated with $340 \mathrm{nmol} / \mathrm{L}$ insulin for $4 \mathrm{~h}$ and leptin RNA and protein levels were assessed respectively by QRT-PCR and immunofluorescence/deconvoluted microscopy. In parallel, to examine the efficacy of siRNA treatments, HIF- $1 \alpha$ and Spl expression levels were determined by immunoblotting. In control experiments, targeting siRNAs were replaced with lamin A/C siRNA (Qiagen). The experiments were repeated thrice for HIF-1 $\alpha$, four times for Spl, and thrice for both siRNAs.

Leptin detection by immunofluorescence/deconvoluted microscopy. MDA-MB-231 cells were plated in 2-well Permanox chamber slides (Nunc). Subconfluent cultures were transfected with HIF-1 $\alpha$ siRNA and/or Sp1 siRNA and treated with $340 \mathrm{nmol} / \mathrm{L}$ insulin for $16 \mathrm{~h}$ for leptin detection. Then, the cells were fixed for $10 \mathrm{~min}$ at $-20^{\circ} \mathrm{C}$ in methanol. Next, the cells were permeabilized with $0.2 \%$ Triton $\mathrm{X}-100$ for $5 \mathrm{~min}$, and unspecific binding was blocked with $7.5 \%$ bovine serum albumin fraction $\mathrm{V}$ for $1 \mathrm{~h}$ at room temperature. Leptin expression was detected using $200 \mu \mathrm{g} / \mathrm{mL} \mathrm{Ob}$ pAb A-20 (Santa Cruz) and donkey anti-rabbit IgG-FITC (Santa Cruz). The 


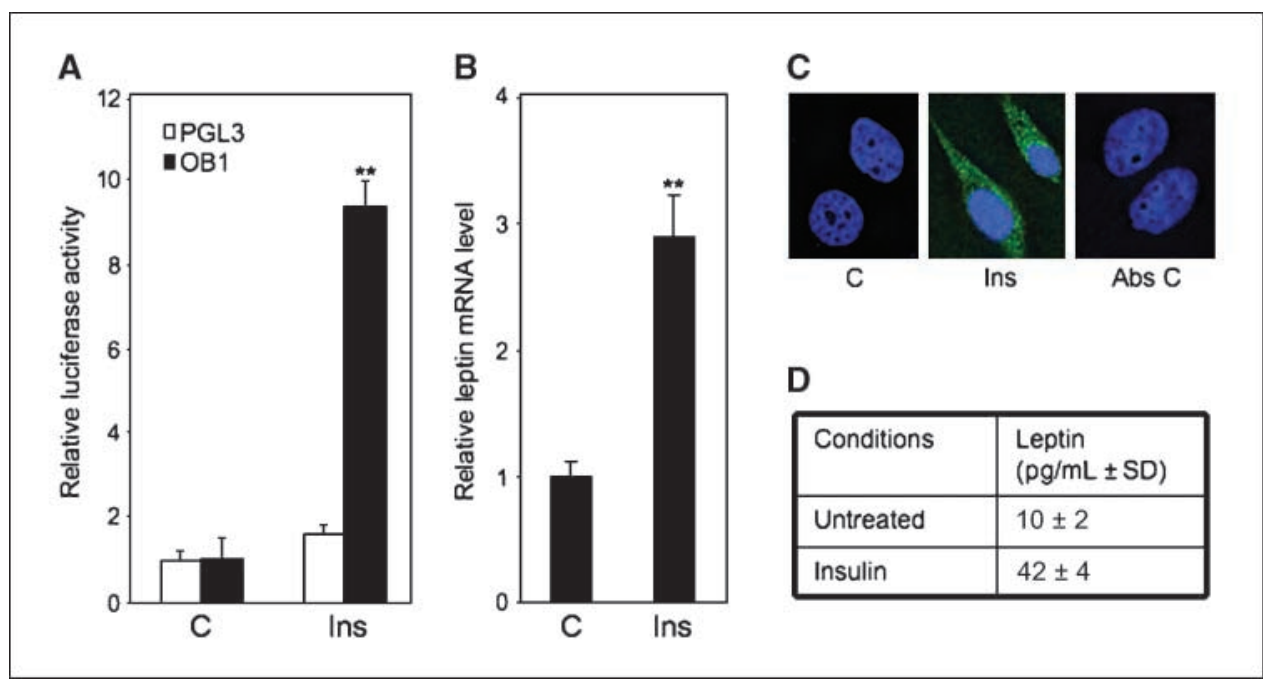

Figure 1. Insulin stimulates leptin promoter activity and leptin expression. $A$, the activation of the leptin promoter was tested in MDA-MB-231 cells with luciferase reporter assay, as described in Materials and Methods. The cells transfected with the control plasmid ( $p G L 3)$ or the leptin promoter-luciferase plasmid (OB1)

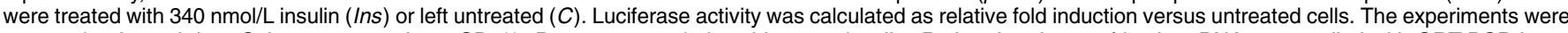
repeated at least thrice. Columns, mean; bars, SD; ${ }^{\star *}, P<0.01$ control plasmid versus insulin. $B$, the abundance of leptin mRNA was studied with $Q R T-P C R$ in

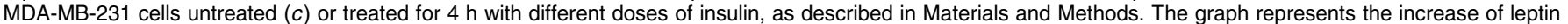
mRNA relative to the increase of $\alpha$-actin mRNA in the same sample $\pm \mathrm{SD}$. ${ }^{*}, P<0.01$, control versus insulin. $C$, MDA-MB-231 cells were treated for $16 \mathrm{~h}$ with

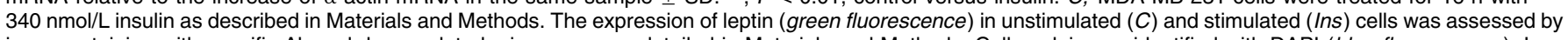
immunostaining with specific Ab and deconvoluted microscopy, as detailed in Materials and Methods. Cell nuclei were identified with DAPI (blue fluorescence). In

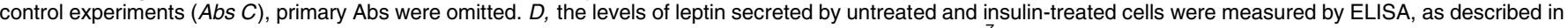
Materials and Methods. The values represent pg leptin/mL conditioned medium obtained from $1.5 \times 10^{7}$ cells. The differences between the two conditions were statistically significant $(P<0.05)$.

slides were covered with Vectashield mounting medium containing $4^{\prime}, 6$ diamidino-2-phenylindole (DAPI; Vector laboratories, Inc.) to allow visualization of cell nuclei. The abundance of leptin under different conditions was assessed using Olympus IX81 deconvoluted microscope and Slidebook software. Leptin expression was quantified by determining the percentage of positive cells in at least 10 viewing fields.

Leptin detection by ELISA. Subconfluent MDA-MB-231 cells were left untreated or were treated for $4 \mathrm{~h}$ with $340 \mathrm{nmol} / \mathrm{L}$ insulin, and/or $50 \mu \mathrm{mol} / \mathrm{L}$ LY, $5 \mu \mathrm{mol} / \mathrm{L}$ UO. After that, the cells were counted and conditioned medium was collected and concentrated with Amicon centrifugal filter $10 \mathrm{~K}$ (Millipore) to final volume of $500 \mu \mathrm{L}$. Leptin concentration in conditioned medium was measured using the Human ELISA kit (R\&D), which specifically detects leptin without significant cross-reactivity or interference with factors related to or associated with leptin. The lowest detectable concentration was $7.8 \mathrm{pg} / \mathrm{mL}$, intra-assay variation was $<4.8 \%$, and interassay variation was $<7.2 \%$. The standard curve was done using $0,7.8,15.6$, $31.2,62.5,125,250,500$, and $1,000 \mathrm{pg} / \mathrm{mL}$ leptin concentrations. Leptin concentrations detected in conditioned medium were within the range of the standard curve. The concentrations are expressed as $\mathrm{pg} / \mathrm{mL}$ per $1.5 \times$ $10^{7}$ cells. All points were done in triplicate and the experiments were repeated thrice.

Statistical analysis. The correlations were studied by Student's $t$ test. $P$ values of $<0.05$ were considered statistically significant.

\section{Results}

Insulin treatment activates the leptin promoter and increases leptin mRNA and protein expression in MDA-MB231 cells. We have previously shown that leptin is overexpressed in human breast cancer biopsies and that this overexpression might be caused by obesity-related stimuli (10). Here, we focused on the molecular mechanism of leptin activation by high doses of insulin in MDA-MB-231 cells.

To assess whether insulin can affect leptin transcriptional activity, we used the reporter plasmid, pGL3-OB1, containing the luciferase gene under the control of leptin regulatory sequences
$(-2,924$ to +31$)$. We found that insulin significantly (by $\sim 5.5$-fold) induced luciferase activity in MDA-MB-231 breast cancer cells transfected with pGL3-OB1, relative to cells transfected with an empty vector pGL3 (Fig. 1A).

Using QRT-PCR, we showed that insulin stimulated leptin mRNA synthesis by $\sim 1.8$-fold, relative to untreated cells. Using immunofluorescence deconvoluted microscopy, we observed that cellular leptin protein was highly expressed in $65 \% \pm 2 \%$ of insulin-treated cells but was detectable only in $10 \% \pm 1 \%$ of control cells (Fig. $1 B$ and $C$ ). Similarly, insulin significantly ( $\sim 4.0$-fold $)$ increased the levels of secreted leptin, as measured by Elisa (Fig. 1D).

Insulin stimulates nuclear expression of HIF-1 $\alpha$ and Spl. Insulin can activate gene transcription through different transcription factors, including both Spl and HIF-dependent mechanisms (32, 37-40). Here, we assessed the abundance of nuclear Spl and HIF- $1 \alpha$ in MDA-MB-231 cells in response to insulin treatment (Fig. 2A). In untreated cells, similar levels of Spl were found in the cytoplasm and nucleus, whereas HIF- $1 \alpha$ was present only in nuclear protein fractions. Insulin stimulation significantly increased nuclear abundance of both factors (Fig. $2 A$ ). The cytoplsmatic protein $\beta$-tubulin and nuclear protein nucleolin were used as control of protein loading.

Insulin stimulates loading of transcription factors on the leptin promoter in MDA-MB-231 cells. To test if insulin stimulates the loading of Spl and HIF- $1 \alpha$ as well as other transcription regulators on the leptin promoter, we first used ChIP assays (Fig. 2B). Because the leptin promoter contains multiple potential HIF and Spl binding sites, we hypothesized that insulin-induced leptin transcription (Fig. 1A) might be related to the increased association of HIF-1 $\alpha$ and Spl with leptin regulatory sequences. Indeed, insulin significantly increased HIF- $1 \alpha$ and Spl binding to two leptin promoter regions: Lep1 region $(-992$ to +377$)$ containing four HRE 
A

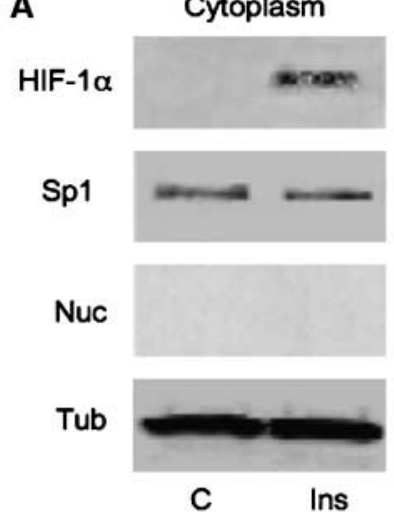

B

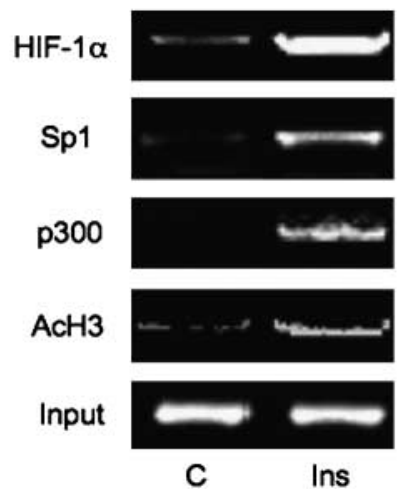

Nucleus
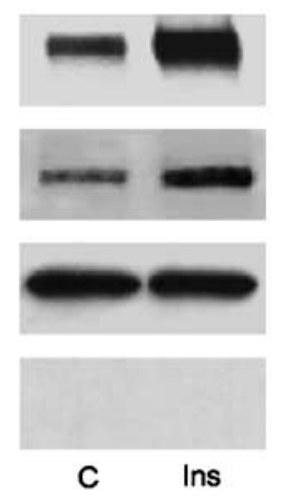

\section{Lep 2 (1339 bp)}
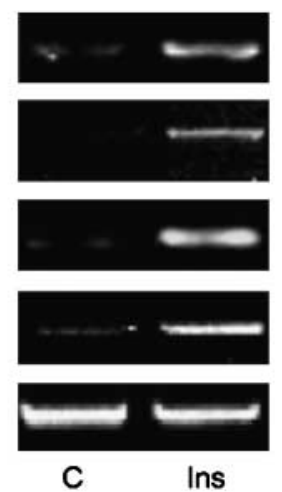
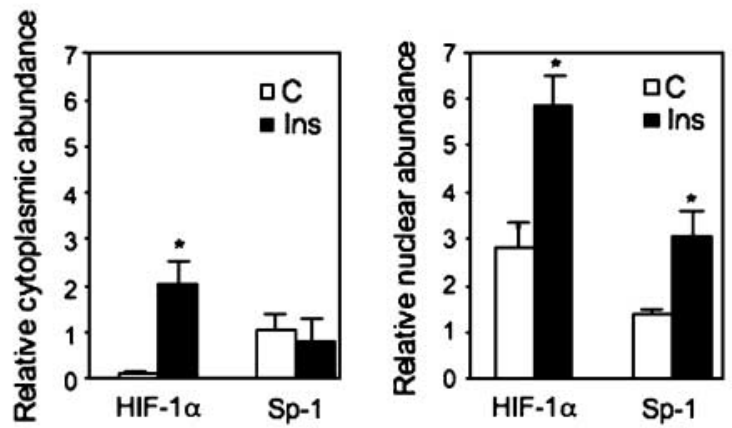

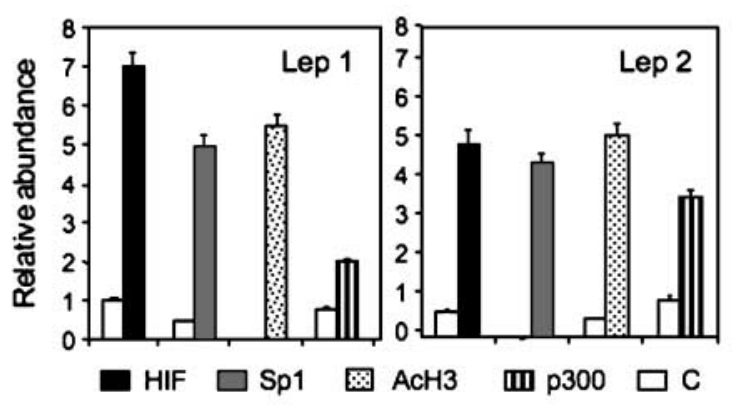

Figure 2. Insulin increases nuclear levels of HIF-1 $\alpha$ and Sp1 and stimulates their loading on the leptin promoter. A, MDA-MB-231 cells were cells treated for $4 \mathrm{~h}$ with $340 \mathrm{nmol} / \mathrm{L}$ insulin or left untreated. The expression of HIF-1 $\alpha(\sim 120 \mathrm{kDa})$ and Sp1 $(\sim 106 \mathrm{kDa})$ was assessed by WB in $70 \mu \mathrm{g}$ of cytoplasmic or nuclear proteins using specific Abs, as described in Materials and Methods. Protein loading and purity of fractions were controlled by reprobing WB filters for the expression of a cytoplasmic protein $\beta$-tubulin (Tub) and a nuclear marker nucleolin $(N u c)$. Graphs represent relative HIF-1 $\alpha$ and Sp1 expression levels normalized to nuclear marker nucleolin or cytoplasmic protein $\beta$-tubulin; columns, mean; bars, SD; ${ }^{*}, P<0.05$, control versus insulin. $B$, soluble chromatin was isolated from MDA-MB-231 cells stimulated with insulin for $4 \mathrm{~h}$, and from untreated cells. The binding of HIF-1 $\alpha, \mathrm{Sp} 1, \mathrm{p} 300$, and acetylated histones $\mathrm{H} 3(A c H 3)$ to two different leptin promoter regions, Lep1 and Lep2, was assessed by ChIP, as described in Materials and Methods. Nonimmune IgG was used as control for precipitating Abs. DNA input in PCR reactions was assessed using Lep1 and Lep2 primers on samples before immuniprecipitations. The graph represents the abundance of HIF-1 $\alpha, \mathrm{Sp} 1, \mathrm{AcH} 3$, or p300 on Lep1 and Lep2 under different conditions \pm SD; ${ }^{*}, P<0.05$, control versus insulin.

consensus sequences $(-765 / 760,-632 /-627,-571 /-566$, and $-120 /-115)$ and five Sp1 binding motifs (-655/-649, -353/ $-343,-128 /-122,-103 /-90$, and $-22 /-16$ ), and Lep2 (region from -2742 to -1403$)$ containing two Spl motifs $(-2539 /-2534$ and $-1913 /-1918)$ and four HRE $(-2593 /-2588,-2467 /-2462$ $-1830 /-1825,-1506 /-1501$; Fig. $2 B$ ). Specifically, under insulin treatment, the recruitment of HIF- $1 \alpha$ increased by $\sim 6$-fold on Lep1 and by $\sim 3.5$-fold on Lep2, relative to untreated cells. Similarly, insulin stimulated the association of Spl by $\sim 3-$ and $\sim 2.5$-fold on Lep1 and Lep2, respectively. In parallel, we noted an increased association of p300, a histone acetyl transferase and a common coregulator of HIF and Sp1 (28-30) with Lep 1 and Lep2, paralleled by higher abundance of acetylated $\mathrm{H} 3$ at these regions (Fig. 2B). Samples precipitated with control IgGs did not reveal any PCR products for Lep 1 or Lep 2 (data not shown).

Inhibition of ERK1/2 and PI-3K pathways down-regulates insulin-dependent leptin mRNA and protein expression. Leptin expression and activity are regulated by insulin-sensitive ERK1/2 and PI-3K/Akt signaling pathways $(41,42)$. Using UO and LY inhibitors, we studied whether these pathways are required for leptin expression in MDA-MB-231 cells. The treatment of cells with
UO inhibited insulin-induced leptin mRNA expression by $\sim 38 \%$. Similar effects were observed with LY (Fig. $3 A$ ). LY, but not UO, also blocked basal leptin mRNA by $\sim 50 \%$ (Fig. $3 A$ ). Similarly, insulindependent leptin levels were reduced by UO and LY by $\sim 38 \%$ and $41 \%$, respectively, whereas basal levels were not significantly affected (Fig. 3B).

Inhibition of PI-3K reduces insulin-dependent binding of HIF-1 $\alpha$, but not of Sp1, to the proximal leptin promoter. PI-3K and ERK-1/2 pathways are known to regulate HIF-1 $\alpha$ expression and activity, whereas Sp1 is influenced mostly by ERK-1/2 (43-46). Here, we studied how inhibition of these pathways can affect insulin-induced recruitment of HIF- $1 \alpha$ and Spl to the leptin promoter. Using ChIP technology, we found that LY significantly (by $\sim 25 \%$ ) reduced insulin-dependent binding of HIF-1 $\alpha$ to Lep1; however, it did not modulate binding of Sp1 to Lep1 or Lep2 regions. Samples precipitated with control IgGs did not reveal any Lep 1 or Lep2 PCR products (Figs. $4 A$ and 6).

Similarly, using DAPA assay, we found that LY inhibited by $\sim 20 \%$ HIF- $1 \alpha$ binding to $-602 /-631$ sequence in Lepl; however, the drug did not affect HIF-1 $\alpha$ interaction with Lep2 or Sp1 associations with any leptin promoter regions (Fig. 4B). Relevant 
unlabeled probes, used as controls, did not precipitate HIF-1 $\alpha$ or Sp1 proteins (data not shown).

Inhibition of ERK-1/2 significantly reduces insulin-dependent binding of HIF-1 $\alpha$ to the proximal and distal leptin promoter and of Spl to the proximal leptin promoter. In the presence of UO, insulin-stimulated HIF-1 $\alpha$ loading on Lep1 was reduced by $\sim 50 \%$ and on Lep2, by $\sim 46 \%$, according to our ChIP analysis. UO also nearly completely blocked the basal level of HIF$1 \alpha$ binding to these regions (Fig. $4 A$ ). Furthermore, UO inhibited insulin-dependent association of Spl with Lep1 by $\sim 62 \%$. However, no effects of UO were noted for Sp1 binding to Lep2 (Fig. 4A). Samples precipitated with control IgGs did not reveal any Lep 1 or Lep2 PCR products. Similar effects of inhibitors were obtained in DAPA assays, where UO down-regulated HIF- $1 \alpha$ binding to $-602 /-631$ and $-2592 /-2562$ sequences in Lep 1 and Lep2, respectively, and reduced the association of Sp1 to -354 / -323 Lep1 region (Fig. 4B).

Insulin-induced expression of leptin in breast cancer cells requires HIF-1 $\alpha$ and Spl. To determine whether HIF- $1 \alpha$ and Spl are required for insulin-dependent leptin expression in breast cancer cells, we inhibited basal and insulin-induced HIF-1 $\alpha$ and Spl expression with RNA interference. Targeting siRNAs downregulated basal HIF- $1 \alpha$ and Spl protein levels by $\sim 98 \%$ and $85 \%$, respectively, whereas unrelated lamin $\mathrm{A} / \mathrm{C}$ siRNAs had no effects on these proteins (Fig. 5A; data not shown). HIF- $1 \alpha$ and Sp1 knockdowns were paralleled by $\sim 47 \%$ and $50 \%$ inhibition of insulin-induced leptin mRNA levels, respectively. Using a mixture of both siRNAs, we observed further $(\sim 70 \%)$ reduction of insulindependent leptin mRNA expression (Fig. $5 B$ ). No significant effects of single siRNAs were seen on basal leptin mRNA expression, but the combination of both siRNAs reduced basal leptin levels by $\sim 50 \%$ (Fig. $5 B$ ). Similarly, siRNAs targeting either HIF-1 $\alpha$, Sp1, or both transcription factors reduced cellular leptin expression by $58 \% \pm 4 \%, 46 \% \pm 2 \%$, and $100 \% \pm 0 \%$, respectively (Fig. $5 C$ )

The hypothetical model of insulin-dependent leptin expression through Spl- and HIF-1 $\alpha$-dependent transcription in MDA-MB231 cells is presented in Fig. 6 .

\section{Discussion}

Pathologic conditions associated with hyperinsulinemia, such as obesity, metabolic syndrome, and diabetes, have been shown to increase the risk of breast cancer $(1,2,5)$. Insulin is known to stimulate breast cancer cell growth and transformation; however, molecular mechanisms of these effects are only partially known (47). Here, we studied how insulin activates the expression of obesity hormone leptin in breast cancer cells.

Studies in cellular and animal models showed that leptin can increase breast cancer cell growth, survival, tumorigenicity, and drug resistance $(2,7)$. Current evidence suggests that leptin is significantly overexpressed in breast cancer relative to noncancer mammary epithelium (10-12). As suggested by our previous work, leptin mRNA overexpression can be induced by obesity-related stimuli, such as insulin, insulin-like growth factor I (IGF-I), estrogens, or hypoxia (10). Interestingly, compared with other mitogens or hypoxia-mimetic agents, insulin was the most effective leptin inducer in ER-negative, metastatic MDA-MB-231 cells (10). Our studies on the molecular mechanism of this phenomenon revealed that: $(a)$ in MDA-MB-231 cells, insulin stimulates leptin mRNA and protein expression, which is associated with transcriptional activation of the leptin gene promoter; $(b)$ insulin increases nuclear accumulation of transcription factors HIF-1 $\alpha$ and Spl and their loading on the leptin promoter, especially association of HIF$1 \alpha$ with $-602 /-631$ and $-2592 /-2562$ sites, and Sp1 with 354/ -323 and $-2540 /-2510$ sites; (c) siRNA-mediated knockdown of either HIF-1 $\alpha$ or Spl significantly down-regulates insulin-induced leptin mRNA and protein expression; this effect is further amplified by double knockdown of both factors; and $(d)$ inhibition of ERK1/2 and PI-3K pathways partially decreases insulin-dependent leptin expression, which is associated with reduced association of HIF-1 $\alpha$ and/or Sp1 with specific leptin promoter regions.

In MDA-MB-231 cells, $340 \mathrm{nmol} / \mathrm{L}$ insulin increased leptin expression through transcriptional mechanism (Figs. 1 and 2). Because the human leptin promoter contains multiple Spl binding sites and HRE motifs, we tested whether these transcription factors are involved in insulin-induced leptin expression. ChIP assays showed that insulin increased nuclear abundance of both Spl and HIF- $1 \alpha$, and elevated binding of these transcription factors to Lep1 and Lep2 promoter regions. These effects were paralleled by increased binding of p300 and acetylation of histone H3 (Fig. 2). Further DAPA analysis proved that within the studied promoter regions, $-602 /-631$ and $-2592 /-2562$ were the preferential HIF-1 $\alpha$ binding sites, and

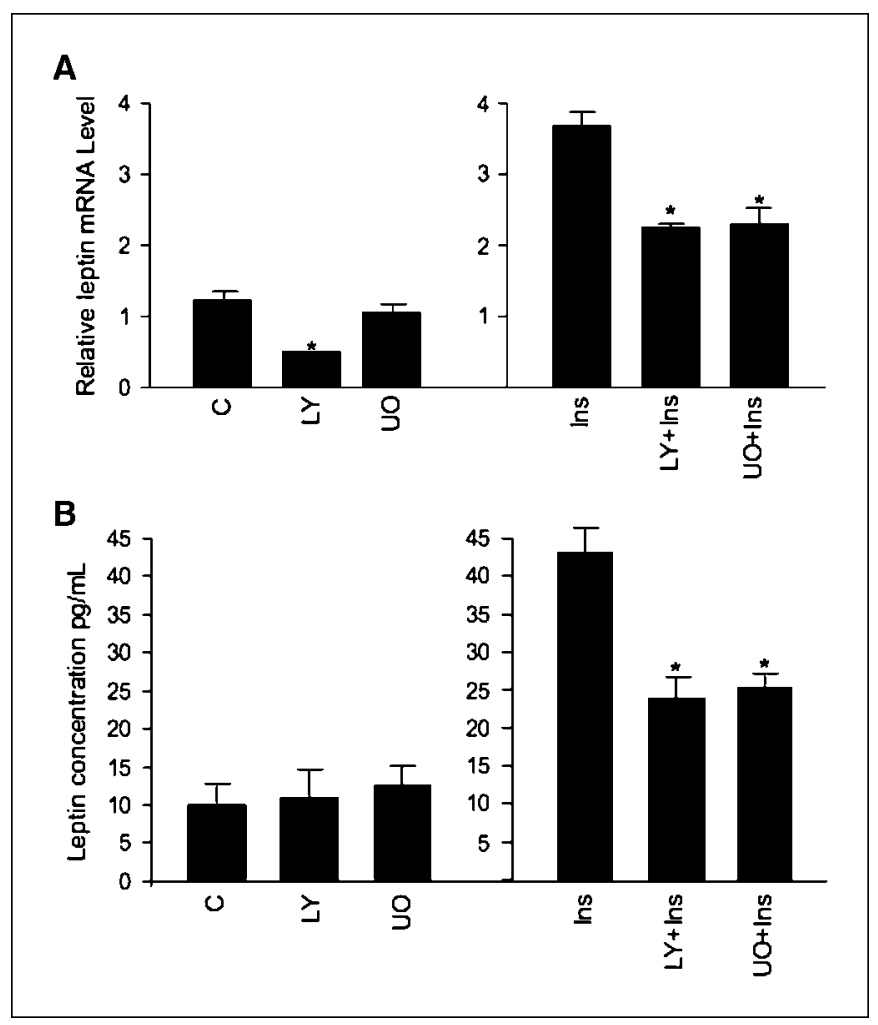

Figure 3. Insulin-induced leptin mRNA and protein expression is mediated by $\mathrm{PI}-3 \mathrm{~K}$ and $\mathrm{ERK} 1 / 2$. A, MDA-MB-231 cells were treated for $4 \mathrm{~h}$ with $340 \mathrm{nmol} / \mathrm{L}$ insulin, and/or $50 \mu \mathrm{mol} / \mathrm{L} \mathrm{LY}$, and/or $5 \mu \mathrm{mol} / \mathrm{L} \mathrm{UO}$, as described in Materials and Methods. The abundance of leptin mRNA was studied with QRT-PCR in MDA-MB-231 cells untreated or treated with insulin, and/or LY, and/or UO as described in Materials and Methods. The graph represents the increase of leptin mRNA relative to the increase of $\alpha$-actin mRNA in the same sample $\pm \mathrm{SD} ;{ }^{*}, P<0.05$ basal versus inhibitor-treated or insulin versus inhibitortreated. $B$, the cells were treated with insulin in the presence or absence of LY or UO. Secreted leptin concentrations were measured as described in Materials and Methods and represent pg leptin per milliliters of conditioned medium from $1.5 \times 10^{7}$ cells. Columns, mean; bars, SDs; ${ }^{*}, P<0.05$ basal versus inhibitor-treated or insulin versus insulin + inhibitor-treated. 


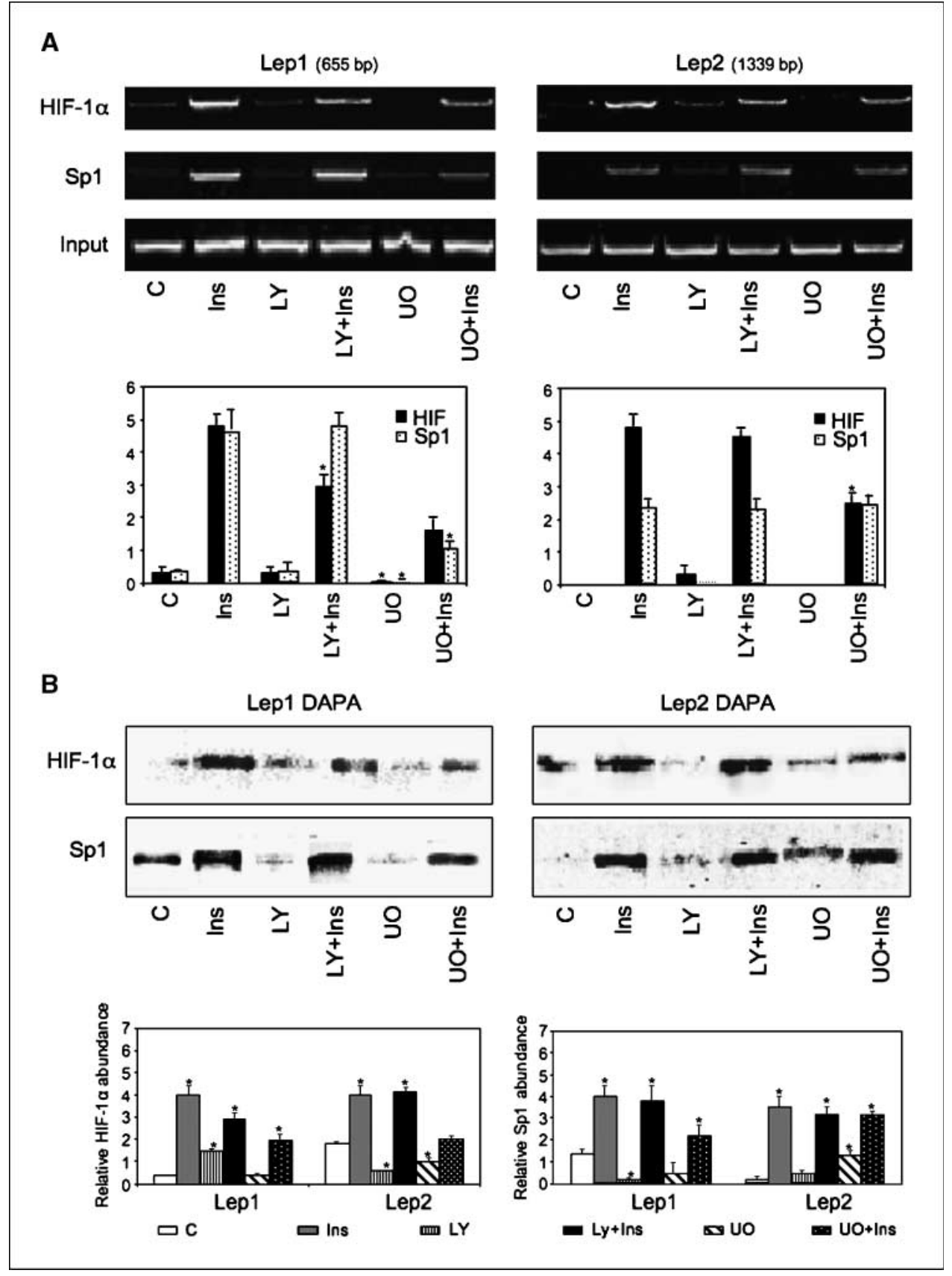

Figure 4. Insulin controls HIF-1 $\alpha$ and Sp1 loading on the leptin promoter. A, MDA-MB-231 cells were treated for $4 \mathrm{~h}$ with insulin, and/or $\mathrm{LY}$, and/or UO or left untreated. The binding of HIF-1 $\alpha$ and Sp1 to Lep1 and Lep2 regions was assessed by ChIP with specific Ab, or control IgG, as described in Materials and Methods. DNA input in PCR reactions was assessed using Lep1 and Lep2 primers on samples before immunoprecipitations. The graph represents relative abundance of HIF-1 $\alpha$ and Sp1 on Lep1 and Lep2 under different conditions \pm SD; ${ }^{*}, P<0.05$ basal versus inhibitor-treated or insulin versus insulin + inhibitor-treated. $B$, the cells were treated as described above. The binding of nuclear HIF-1 $\alpha$ or Sp1 to specific leptin promoter regions was analyzed by DAPA, as described in Materials and Methods. Columns, mean; bars, SD; ${ }^{*}, P<0.05$ basal versus treated samples.

$-354 /-323$ and $-2540 /-2510$ were the sites for Sp1 binding (Figs. 4 and 6). Interestingly, Spl and HIF- $1 \alpha$ did not associate with other individual consensus sites in response to insulin (data not shown). This could reflect true transcriptional preferences under insulin treatment, or be simply related to high CG content and tertiary structures of our DNA-DAPA probes and their poor hybridization with transcription factors in vitro. Interestingly, in ChIP assays, loading of HIF- $1 \alpha$ and Spl tended to be more abundant on Lep1 than on Lep2, possibly due to preferential chromatin structure within the region containing $-602 /-631$ HRE and $-354 /-323$ Spl motifs (Fig. 6).

The importance of HIF- $1 \alpha$ and Spl for leptin mRNA and protein expression was confirmed using specific siRNAs. Indeed, downregulation of both transcription factors produced nearly complete inhibition of insulin-dependent leptin mRNA expression and resulted in total blockade of insulin-induced leptin protein expression (Fig. 5). This is in agreement with the notion that HIF- $1 \alpha$ and Spl cooperate in the regulation of insulin-induced 
leptin transcription in adipocytes (17). However, effective downregulation of HIF- $1 \alpha(98 \%)$ and Spl $(85 \%)$ did not produce similarly profound effects on leptin mRNA, suggesting that other transcription factors might be involved.

The transcriptional activity of the leptin promoter seemed to be differentially regulated by PI-3K and ERK1/2, two major pathways activated by insulin. The ERK1/2 pathway controlled the association of HIF-1 $\alpha$ with Lep1 and Lep2 as well as Sp1 binding to Lep1, which might be related to significant regulation of both factors by ERK-1/ 2 -dependent phosphorylation $(27,43,44)$. On the other hand, PI-3K regulated HIF- $1 \alpha$ binding only on the proximal Lep1 promoter region (Figs. 4 and 6). Interestingly, loading of Sp1 on Lep2 was not blocked by the PI-3K or ERK1/2 inhibitors (Figs. 4 and 6), suggesting that insulin used other pathways, for instance PKC $\alpha$ to phosphorylate Sp1 and activate Sp1/DNA interaction (48). Insulin could also affect leptin transcription through crosstalk with other receptors or intracellular kinases, such as src. The substantial, albeit partial, involvement of the PI-3K and ERK1/2 pathways in insulin- dependent leptin mRNA and protein expression was confirmed by QRT-PCR and ELISA data (Fig. 3). The basal leptin mRNA and protein expression seemed to be regulated by HIF and Spl, and PI-3K could be involved on the transcriptional level (Figs. 3 and 5). Although PI-3K might influence basal HIF activity, it is not clear which pathways affected basal Spl activity.

Our results demonstrating insulin-dependent leptin transcription in MDA-MB-231 breast cancer cells are in agreement with data obtained in other cells models $(17,36)$. We are the first to show that in MDA-MB-231 cells, insulin-induced leptin expression is regulated by PI-3K and ERK1/2 pathways and requires Sp1- and HIF$1 \alpha-$ mediated transcription. Previously, we showed that MCF-7 breast cancer cells can produce leptin in response to estradiol, insulin, IGF-I treatment, as well as in response to physiologic or pharmacologic hypoxia (10). However, in MCF-7 cells, the action of insulin was mediated by HIF-1 $\alpha$, although Spl was not involved (data not shown; ref. 32). This implicates that the mechanisms of leptin synthesis in breast tumors might be cell context-dependent;
Figure 5. HIF-1 $\alpha$ and Sp1 knockdowns reduce leptin expression. A, MDA-MB-231 cells were transfected with HIF- $1 \alpha$ or Sp1 siRNA, as described in Materials and Methods, or were left untransfected. In control experiments, the cells were transfected with lamin A/C siRNA. The expression of HIF-1 $\alpha$ and $\mathrm{Sp} 1$ in $50 \mu \mathrm{g}$ of total cell lysates was determined by WB. Columns, mean; bars, SD; ${ }^{*}, P<0.05$ control versus treated samples. $B$, the expression of leptin mRNA in HIF- $1 \alpha$ and Sp1 siRNA transfectants treated with insulin for $4 \mathrm{~h}$ or left untreated was studied by QRT-PCR. Columns, mean; bars, SD; * $P<0.05$ basal versus treated or insulin versus treated samples. $C$, the expression of leptin protein after $16 \mathrm{~h}$ of insulin treatment was visualized by immunofluorescence and deconvoluted microscopy. The expression of $\beta$-tubulin was assessed as control of protein loading.

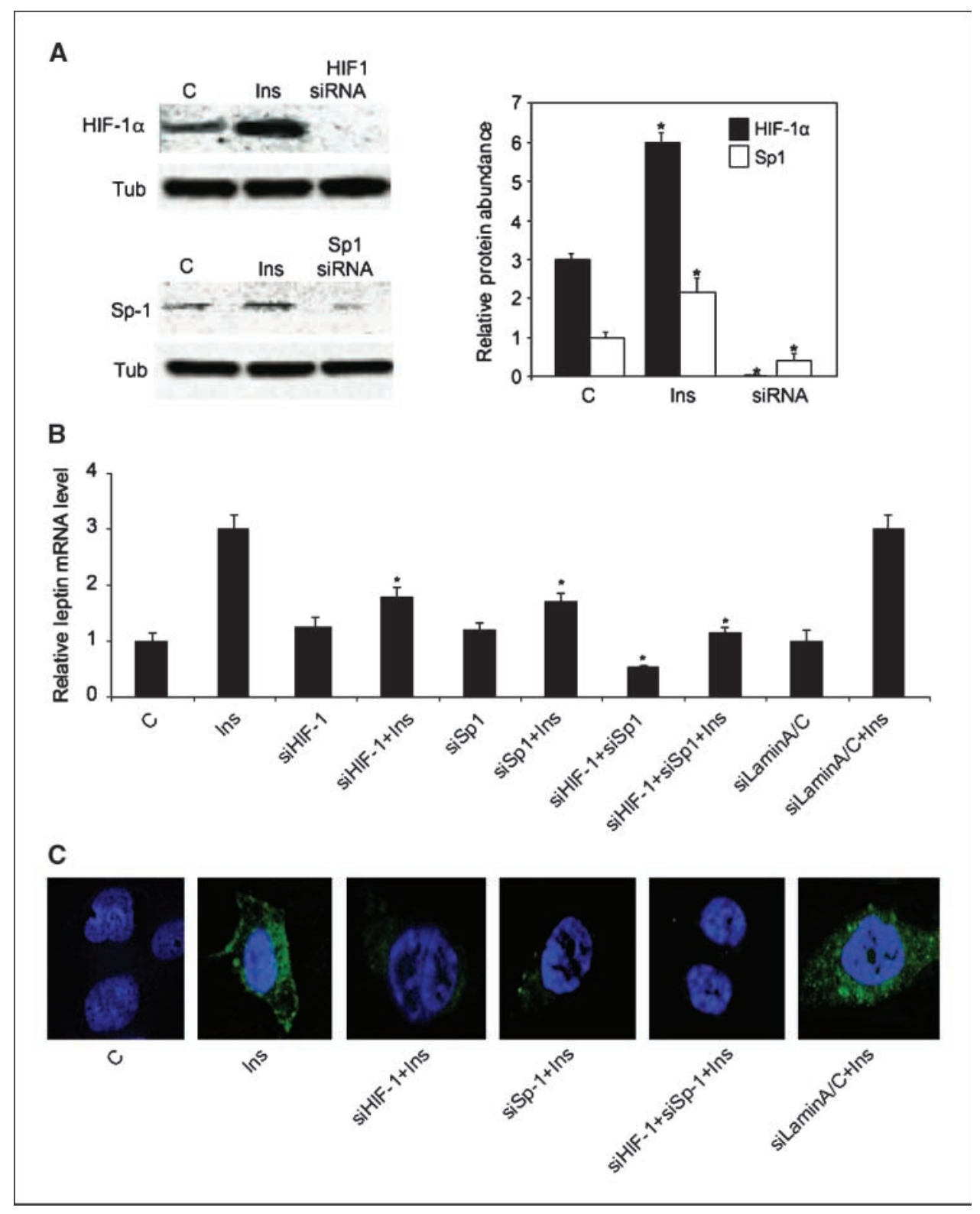




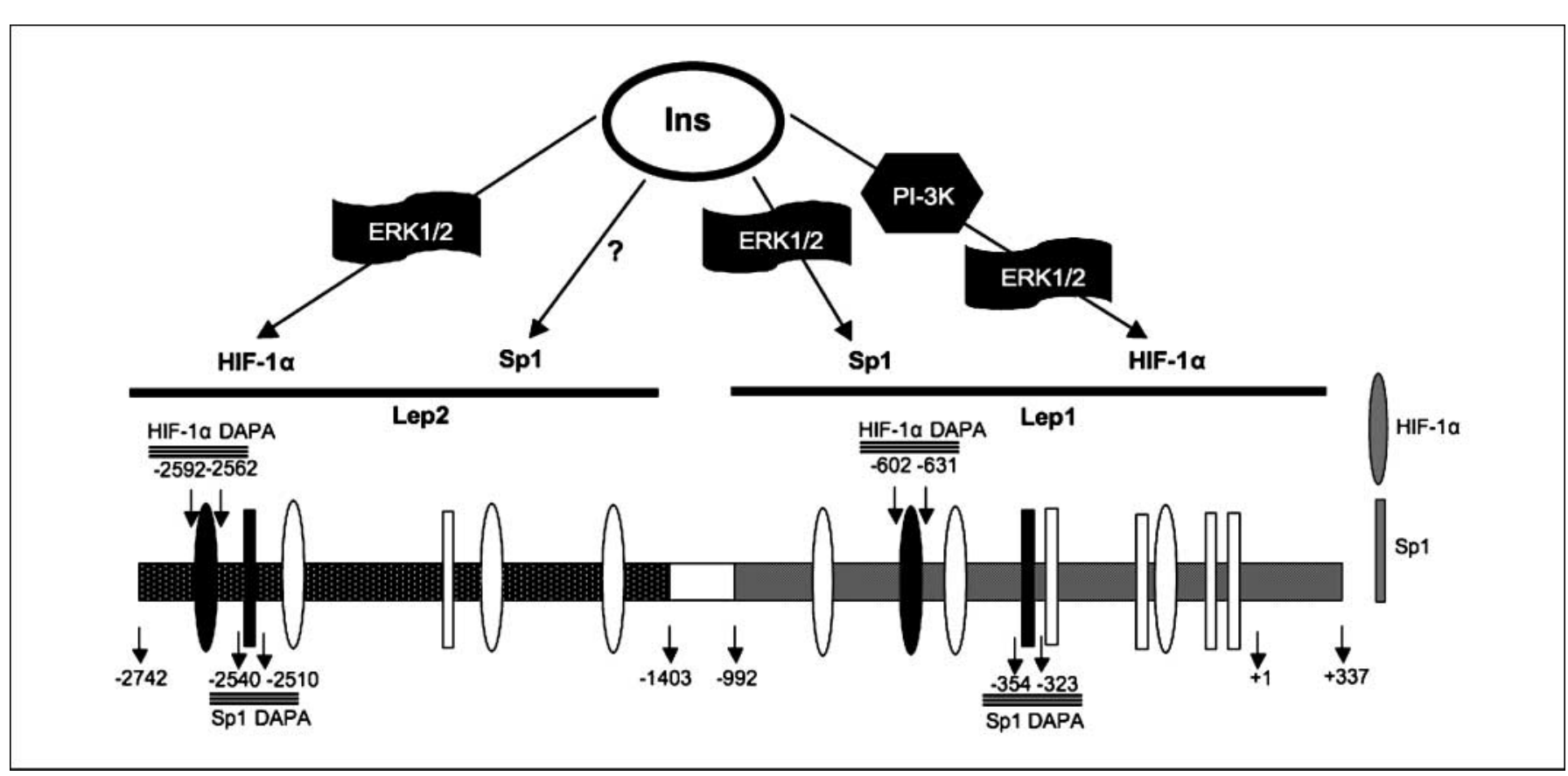

Figure 6. Model of insulin-induced leptin transcription in MDA-MB-231 cells. Insulin induces HIF-1 $\alpha$ and Sp1 binding with the leptin promoter regions Lep1 and Lep2. Potential HIF-1 $\alpha$ and Sp1 binding sites are indicated by open ovals or rectangles, respectively, whereas identified by DAPA sites are indicated by black shapes. Association of HIF-1 $\alpha$ with Lep1 is controlled in part by PI-3K and ERK1/2. Binding of Sp1 to Lep1 is enhanced by ERK-1/2. On Lep2, binding of HIF-1 $\alpha$ is partially controlled by ERK1/2, whereas neither PI-3K nor ERK1/2 modulates Sp1 association.

for instance, the process is somehow dependent on the presence or absence of ER, as this receptor is know to influence insulin and IGF-I signaling pathways and their outcome $(33,49)$.

In summary, our data suggest that hyperinsulinemia could induce breast cancer progression through leptin-dependent mechanisms.

\section{Disclosure of Potential Conflicts of Interest}

No potential conflicts of interest were disclosed.

\section{Acknowledgments}

Received 8/17/2007; revised 4/4/2008; accepted 4/17/2008

Grant support: WW Smith Charitable Trust (E. Surmacz), Sbarro Health Research Organization (E. Surmacz), and a fellowship from Fondazione Italiana per la Ricerca sul Cancro (S. Cascio).

The costs of publication of this article were defrayed in part by the payment of page charges. This article must therefore be hereby marked advertisement in accordance with 18 U.S.C. Section 1734 solely to indicate this fact.

The Obl plasmid was a gift from Prof. Auwerx. Institut de Génétique et de Biologie Moléculaire et Cellulaire, Centre National de la Recherche Scientifique/Institut National de la Sante et de la Recherche Medicale/Université Louis Pasteur, Illkirch, France.

\section{References}

1. Calle EE, Thun MJ. Obesity and cancer. Oncogene 2004;23:6365-78.

2. Schaffler A, Scholmerich J, Buechler C. Mechanisms of disease: adipokines and breast cancer - endocrine and paracrine mechanisms that connect adiposity and breast cancer. Nat Clin Pract Endocrinol Metab 2007;3:345-54.

3. Surmacz E. Obesity hormone leptin: a new target in breast cancer? Breast Cancer Res 2007;9:301.

4. Lorincz AM, Sukumar S. Molecular links between obesity and breast cancer. Endocr Relat Cancer 2006;13: 279-92.

5. Vona-Davis L, Rose DP. Adipokines as endocrine, paracrine, and autocrine factors in breast cancer risk and progression. Endocr Relat Cancer 2007;14:189-206.

6. Zhang F, Chen Y, Heiman M, Dimarchi R. Leptin: structure, function and biology. Vitam Horm 2005;71: 345-72.

7. Garofalo C, Surmacz E. Leptin and cancer. J Cell Physiol 2006;207:12-22.

8. Mauro L, Catalano S, Bossi G, et al. Evidences that leptin up-regulates E-cadherin expression in breast cancer: effects on tumor growth and progression. Cancer Res 2007;67:3412-21.

9. Saxena NK, Vertino PM, Anania FA, Sharma D. Leptininduced growth stimulation of breast cancer cells involves recruitment of histone acetyltransferases and mediator complex to CYCLIN D1 promoter via activation of Stat3. J Biol Chem 2007;282:13316-25.

10. Garofalo C, Koda M, Cascio $S$, et al. Increased expression of leptin and the leptin receptor as a marker of breast cancer progression: possible role of obesityrelated stimuli. Clin Cancer Res 2006;12:1447-53.

11. Ishikawa $M$, Kitayama J, Nagawa $H$. Enhanced expression of leptin and leptin receptor (OB-R) in human breast cancer. Clin Cancer Res 2004;10:4325-31. 12. Revillion $F$, Charlier M, Lhotellier V, et al. Messenger RNA expression of leptin and leptin receptors and their prognostic value in 322 human primary breast cancers. Clin Cancer Res 2006;12:2088-94.

13. Lipscombe LL, Goodwin PJ, Zinman B, McLaughlin JR, Hux JE. Diabetes mellitus and breast cancer: a retrospective population-based cohort study. Breast Cancer Res Treat 2006;98:349-56.

14. Pasanisi P, Berrino F, De Petris M, Venturelli E, Mastroianni A, Panico S. Metabolic syndrome as a prognostic factor for breast cancer recurrences. Int $\mathrm{J}$ Cancer 2006;119:236-8.

15. Gong DW, Bi S, Pratley RE, Weintraub BD. Genomic structure and promoter analysis of the human obese gene. J Biol Chem 1996;271:3971-4.

16. Egea M, Meton I, Baanante IV. Spl and Sp3 regulate glucokinase gene transcription in the liver of gilthead sea bream (Sparus aurata). J Mol Endocrinol 2007;38: 481-92.

17. Meissner U, Ostreicher I, Allabauer I, Rascher W, Dotsch J. Synergistic effects of hypoxia and insulin are regulated by different transcriptional elements of the human leptin promoter. Biochem Biophys Res Commun 2003;303:707-12

18. Lam JK, Matsubara $S$, Mihara $K$, Zheng $X L$, Mooradian AD, Wong NC. Insulin induction of apolipoprotein AI, role of Spl. Biochemistry 2003;42:2680-90. 19. Horovitz-Fried M, Jacob AI, Cooper DR, Sampson SR Activation of the nuclear transcription factor SP-1 by insulin rapidly increases the expression of protein kinase C $\delta$ in skeletal muscle. Cell Signal 2007;19:556-62. 20. Zheng XL, Matsubara S, Diao C, Hollenberg MD, Wong NC. Epidermal growth factor induction of apolipoprotein A-I is mediated by the Ras-MAP kinase cascade and Spl. J Biol Chem 2001;276:13822-9.

21. Cieslik K, Lee CM, Tang JL, Wu KK. Transcriptional regulation of endothelial nitric-oxide synthase by an interaction between casein kinase 2 and protein phosphatase 2A. J Biol Chem 1999;274:34669-75. 22. Ke Q, Costa M. Hypoxia-inducible factor-1 (HIF-1) Mol Pharmacol 2006;70:1469-80.

23. Hirota K, Semenza GL. Regulation of angiogenesis by hypoxia-inducible factor 1 . Crit Rev Oncol Hematol 2006:59:15-26. 
24. Feldser D, Agani F, Iyer NV, Pak B, Ferreira G, Semenza GL. Reciprocal positive regulation of hypoxiainducible factor $1 \alpha$ and insulin-like growth factor 2 . Cancer Res 1999;59:3915-8

25. Richard DE, Berra E, Gothie E, Roux D, Pouyssegur J. p42/p44 mitogen-activated protein kinases phosphorylate hypoxia-inducible factor $1 \alpha(\mathrm{HIF}-1 \alpha)$ and enhance the transcriptional activity of HIF-1. J Biol Chem 1999; 274:32631-7.

26. Liu YZ, Thomas NS, Latchman DS. CBP associates with the p42/p44 MAPK enzymes and is phosphorylated following NGF treatment. Neuroreport 1999;10: 1239-43.

27. Sang N, Stiehl DP, Bohensky J, Leshchinsky I, Srinivas V, Caro J. MAPK signaling up-regulates the activity of hypoxia-inducible factors by its effects on p300. J Biol Chem 2003;278:14013-9.

28. Xiao H, Hasegawa T, Isobe K. p300 collaborates with Spl and Sp3 in p21(wafl/cipl) promoter activation induced by histone deacetylase inhibitor. J Biol Chem 2000;275:1371-6.

29. Ebert BL, Bunn HF. Regulation of transcription by hypoxia requires a multiprotein complex that includes hypoxia-inducible factor 1 , an adjacent transcription factor, and p300/CREB binding protein. Mol Cell Biol 1998;18:4089-96.

30. Gray MJ, Zhang J, Ellis LM, et al. HIF-1 $\alpha$, STAT3, CBP/ p300 and Ref-1/APE are components of a transcriptional complex that regulates Src-dependent hypoxia-induced expression of VEGF in pancreatic and prostate carcinomas. Oncogene 2005;24:3110-20.

31. Grosfeld A, Andre J, Hauguel-De Mouzon S, Berra E, Pouyssegur J, Guerre-Millo M. Hypoxia-inducible factor 1 transactivates the human leptin gene promoter. J Biol Chem 2002;277:42953-7.
32. Cascio S, Bartella V, Auriemma A, et al. Mechanism of leptin expression in breast cancer cells: role of hypoxiainducible factor- $1 \alpha$. Oncogene 2008;27:540-7.

33. Bartucci M, Morelli C, Mauro L, Ando S, Surmacz E. Differential insulin-like growth factor I receptor signaling and function in estrogen receptor (ER)-positive MCF-7 and ER-negative MDA-MB-231 breast cancer cells. Cancer Res 2001;61:6747-54.

34. Morelli C, Garofalo C, Sisci D, et al. Nuclear insulin receptor substrate 1 interacts with estrogen receptor $\alpha$ at ERE promoters. Oncogene 2004;23:7517-26.

35. Miller SG, De Vos P, Guerre-Millo $M$, et al. The adipocyte specific transcription factor $\mathrm{C} / \mathrm{EBP} \alpha$ modulates human ob gene expression. Proc Natl Acad Sci U S A 1996;93:5507-11.

36. Cascio S, Bartella V, Garofalo C, Russo A, Giordano A, Surmacz E. Insulin-like growth factor 1 differentially regulates estrogen receptor-dependent transcription at estrogen response element and AP-1 sites in breast cancer cells. J Biol Chem 2007;282:3498-506.

37. Wang F, Li SS, Segersvard R, et al. Hypoxia inducible factor-1 mediates effects of insulin on pancreatic cancer cells and disturbs host energy homeostasis. Am J Pathol 2007;170:469-77.

38. Dimova EY, Kietzmann T. The MAPK pathway and HIF-1 are involved in the induction of the human PAIgene expression by insulin in the human hepatoma cell line HepG2. Ann N Y Acad Sci 2006;1090:355-67. 39. Moreno-Aliaga MJ, Swarbrick MM, Lorente-Cebrian S, Stanhope KL, Havel PJ, Martinez JA. Spl-mediated transcription is involved in the induction of leptin by insulin-stimulated glucose metabolism. J Mol Endocrinol 2007;38:537-46.

40. Zelzer E, Levy Y, Kahana C, Shilo BZ, Rubinstein M, Cohen B. Insulin induces transcription of target genes through the hypoxia-inducible factor HIF-1 $\alpha /$ ARNT. EMBO J 1998;17:5085-94.

41. Saxena NK, Sharma D, Ding X, et al. Concomitant activation of the JAK/STAT, PI3K/AKT, and ERK signaling is involved in leptin-mediated promotion of invasion and migration of hepatocellular carcinoma cells. Cancer Res 2007;67:2497-507.

42. Chen C, Chang YC, Liu CL, Chang KJ, Guo IC. Leptininduced growth of human ZR-75-1 breast cancer cells is associated with up-regulation of cyclin D1 and c-Myc and down-regulation of tumor suppressor p53 and p21WAF1/ CIP1. Breast Cancer Res Treat 2006;98:121-32.

43. Minet E, Arnould T, Michel G, et al. ERK activation upon hypoxia: involvement in HIF-1 activation. FEBS Lett 2000;468:53-8.

44. Merchant JL, Du M, Todisco A. Spl phosphorylation by Erk 2 stimulates DNA binding. Biochem Biophys Res Commun 1999;254:454-61.

45. Semenza GL. HIF-1 and tumor progression: pathophysiology and therapeutics. Trends Mol Med 2002;8: S62-7.

46. Michiels C, Minet E, Michel G, Mottet D, Piret JP, Raes M. HIF-1 and AP-1 cooperate to increase gene expression in hypoxia: role of MAP kinases. IUBMB Life 2001;52:49-53.

47. Belfiore A. The role of insulin receptor isoforms and hybrid insulin/IGF-I receptors in human cancer. Curr Pharm Des 2007;13:671-86.

48. Horovitz-Fried M, Sampson SR. Involvement of PKC $\alpha$ in insulin-induced PKC $\delta$ expression: Importance of SP-1 and NFkB transcription factors. Biochem Biophys Res Commun 2007;352:78-83.

49. Surmacz E, Bartucci M. Role of estrogen receptor $\alpha$ in modulating IGF-I receptor signaling and function in breast cancer. J Exp Clin Cancer Res 2004;23:385-94. 